\title{
Correction to: Physician Knowledge of Human Genetic Variation, Beliefs About Race and Genetics, and Use of Race in Clinical Decision-making
}

\author{
Sherrill L. Sellers ${ }^{1}$ (D) Brooke A. Cunningham ${ }^{2}$. Vence L. Bonham ${ }^{3}$
}

Published online: 22 March 2019

(C) W. Montague Cobb-NMA Health Institute 2019

\section{Correction to: Journal of Racial and Ethnic Health Disparities (2019) 6:110-116 \\ https://doi.org/10.1007/s40615-018-0505-y}

We discovered that two of the items in the knowledge index were incorrectly identified. We reran all the analyses and none of the major findings changed. However, we would like to correct the error since our hope is that others will use the measure. The items in the GKAI are listed below and the correct mean GKAI score is 3.28 (Table 1). The regression analysis (Table 2) shows two indicators, "US born vs. Foreign Born" and "Patient Population: Greater than 20\% Minority vs. Less than 20\% Minority" changed from highly significant $(p=.01)$ to significant $(p=.05)$. All other significance levels were unchanged. The model fit was also unchanged.

$10.1007 / \mathrm{s} 40615-018-0505-\mathrm{y}$

Sherrill L. Sellers

slsellers@miamioh.edu

Brooke A. Cunningham

bcunning@umn.edu

Vence L. Bonham

bonhamv@nih.gov

1 College of Education, Health \& Society, Miami University, 210 E. Spring Street, Oxford, OH 45056, USA

2 Department of Family Medicine and Community Health, University of Minnesota Medical School, 717 Delaware Street Se, Rm 420, MMC 381, Minneapolis, MN 55414, USA

3 Social and Behavioral Research Branch, National Human Genome Research Institute, National Institutes of Health, 31 Center Drive Room B1B37-G, Bethesda, MD 20892, USA
Items in the knowledge index are:

\begin{tabular}{lll}
\hline ITEM\# & QUESTION & ANSWER \\
\hline GKAI1 & $\begin{array}{c}\text { The DNA sequences of two randomly } \\
\text { selected healthy individuals of the } \\
\text { same sex are 90-95\% identical. } \\
\text { Most common diseases, such as diabetes } \\
\text { and heart disease, are caused by } \\
\text { a single gene variant. }\end{array}$ & False \\
All the genetic variation in an individual \\
can be attributed to either spontaneous \\
(i.e., de novo) or inherited changes \\
in the human genome.
\end{tabular}


Table 1 Sample Characteristics

Variable

Physicians' Demographics

US Born (\%)

Self-reported Race (\%)

White, non-Hispanic

Minority

Medical Training \& Clinical Experience

Years in Practice [mean (SD)] $16.9(9.8)$

Internal Medicine (\%) $\quad 87.0$

Current Genetics Has Relevance (\% Agree) 71.8

Had Genetics Training in Primary Specialty Residency (\%) 11.3

Type of Degree (\%)

MD

DO

Practice Characteristics

$\begin{array}{ll}\text { RACE [mean, (SD)] } & 13.8(5.6) \\ \text { Knowledge Score [mean (SD)] } & 3.28(1.2) \\ \text { Biological Beliefs [mean (SD)] } & 11.0(3.4) \\ \text { Clinical Beliefs [mean (SD)] } & 11.7(2.4) \\ \text { Patient Panel Over 20\% Minority (\%) } & 74.0\end{array}$

Table 2 OLS Regression Analysis Associations of Physician Knowledge of Genetic Variation and Beliefs about the Biological and Clinical Importance of Race with Use of Race in Clinical Decision-making

\begin{tabular}{lll}
\hline & $(\mathrm{b}) \dagger$ & $(\mathrm{se})$ \\
\hline Physicians' Demographics & & \\
Age & $0.112^{*}$ & 0.047 \\
Self-reported Race: White, non-Hispanic vs. Minority & -0.521 & 0.444 \\
US Born vs. Foreign Born & $-0.897^{*}$ & 0.458 \\
Medical Training \& Clinical Experience & & \\
Years in Practice & -0.072 & 0.047 \\
Internal Medicine Specialty vs. Other Fields & $1.459^{* *}$ & 0.522 \\
Genetic Training in Residency vs. No Genetic Training & 0.797 & 0.541 \\
Current Genetics Relevance: Disagree vs. Agree & $0.703^{* * *}$ & 0.138 \\
MD vs. DO & $-2.491^{* *}$ & 0.807 \\
Practice Characteristics & & \\
Intercept & -2.15503 & 2.243 \\
Knowledge & 0.125 & 0.148 \\
Biological Belief & $0.505^{* * *}$ & 0.057 \\
Clinical Belief & $0.720^{* * *}$ & 0.079 \\
Patient Population: Greater than $20 \%$ Minority vs. Less than $20 \%$ Minority & $0.995^{*}$ & 0.400 \\
\hline
\end{tabular}

R-squared for this model $=0.391 ; \mathrm{F}$-value $=35.10, P$ value $<0.0001$

$\dagger$ coefficient gives the change in the RACE score for every 1 unit increase (e.g. every additional point in score for biological beliefs) or between the indicated group and reference group (e.g. genetic training in primary residency vs. no genetic training)

$* P<0.05, * * P<0.01, * * * P<0.001$

Publisher's Note Springer Nature remains neutral with regard to jurisdictional claims in published maps and institutional affiliations. 